\section{BMJ Open \\ Respiratory \\ Research}

\title{
A national survey of the diagnosis and management of suspected ventilator- associated pneumonia
}

\author{
Emma Browne, ${ }^{1}$ Thomas P Hellyer, ${ }^{1}$ Simon V Baudouin, ${ }^{1}$ Andrew Conway Morris, ${ }^{2}$ \\ Vanessa Linnett, ${ }^{3}$ Danny F McAuley, ${ }^{4}$ Gavin D Perkins, ${ }^{5}$ A John Simpson ${ }^{1}$
}

To cite: Browne $\mathrm{E}$, Hellyer TP, Baudouin SV, et al. A national survey of the diagnosis and management of suspected ventilatorassociated pneumonia. BMJ Open Resp Res 2014;1: e000066. doi:10.1136/ bmjresp-2014-000066

- Additional material is available. To view please visit the journal (http://dx.doi.org/ 10.1136/bmjresp-2014000066)

Received 23 September 2014 Revised 10 November 2014 Accepted 12 November 2014

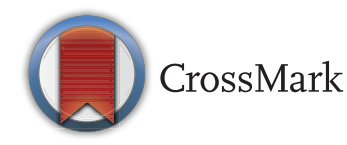

For numbered affiliations see end of article.

Correspondence to Dr Emma Browne; emurielbrowne@yahoo.co.uk

\section{ABSTRACT}

Background: Ventilator-associated pneumonia (VAP) affects up to $20 \%$ of patients admitted to intensive care units (ICU). It is associated with increased morbidity, mortality and healthcare costs. Despite published guidelines, variability in diagnosis and management exists, the extent of which remains unclear. We sought to characterise consultant opinions surrounding diagnostic and management practice for VAP in the UK. Methods: An online survey was sent to all consultant members of the UK Intensive Care Society $(n=\sim 1500)$. Data were collected regarding respondents' individual practice in the investigation and management of suspected VAP including use of diagnostic criteria, microbiological sampling, chest X-ray (CXR), bronchoscopy and antibiotic treatments.

Results: 339 (23\%) responses were received from a broadly representative spectrum of ICU consultants. All respondents indicated that microbiological confirmation should be sought, the majority (57.8\%) stating they would take an endotracheal aspirate prior to starting empirical antibiotics. Microbiology reporting services were described as qualitative only by $29.7 \%$. Only $17 \%$ of respondents had access to routine reporting of CXRs by a radiologist. Little consensus exists regarding technique for bronchoalveolar lavage (BAL) with the reported volume of saline used ranging from 5 to $500 \mathrm{~mL} .24 .5 \%$ of consultants felt inadequately trained in bronchoscopy.

Conclusions: There is wide variability in the approach to diagnosis and management of VAP among UK consultants. Such variability challenges the reliability of the diagnosis of VAP and its reported incidence as a performance indicator in healthcare systems. The data presented suggest increased radiological and microbiological support, and standardisation of BAL technique, might improve this situation.

\section{INTRODUCTION}

Ventilator-associated pneumonia (VAP) is a common nosocomial infection affecting up to $20 \%$ of patients admitted to intensive care units (ICUs) ${ }^{1-3}$ VAP is associated with a 2-7fold increased risk of death ${ }^{4}{ }^{5}$; although the actual attributable mortality of VAP has proven difficult to determine with a wide range of

\section{KEY MESSAGES}

Despite guidelines, marked variation in the diagnosis and management of ventilator-associated pneumonia (VAP) continues to exist within the UK.

- Until a consensus approach is reached the use of VAP rates as a performance indicator in healthcare systems is unreliable.

Increased radiological and microbiological support may improve the diagnosis of VAP.

Better training in the performance of bronchoalveolar lavage (BAL) may lead to increased delivery of high-quality BAL and improved diagnosis of VAP.

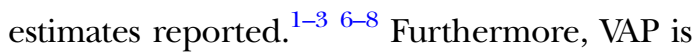
associated with excess morbidity and healthcare costs, increasing hospital length of stay by an average of 4-9 days. ${ }^{156}$ Despite the introduction of preventive measures aimed at reducing VAP rates it remains prevalent within ICUs. This has led to the incidence of VAP being adopted as a performance indicator in some healthcare systems. In turn, this has drawn further attention to the significant challenges the condition presents in terms of diagnosis and management. The lack of consensus as to diagnostic criteria or the 'gold standard' diagnostic test has hampered research development over recent years and more recently has led to discrepancies in clinical VAP rates and reported surveillance rates. ${ }^{9}$

Although guidelines have been published, ${ }^{10-12}$ variability in the approach to diagnostic procedures and management of VAP exists and is poorly defined. We therefore sought to characterise consultant opinion surrounding diagnostic and management practice for VAP in the UK.

\section{METHODS}

All consultant members of the UK Intensive Care Society were invited to take part in an online survey. A survey tool was developed 
and piloted in a local ICU prior to distribution nationally. The survey collected data regarding demographics of the respondents' place of work and their individual practice in the investigation and management of suspected VAP including use of diagnostic criteria, microbiological sampling, chest X-ray (CXR), bronchoscopy and bronchoalveolar lavage (BAL) and antibiotic treatments.

The survey was hosted by the Survey Monkey website (http://www.surveymonkey.com). An email inviting participation was sent to all consultant members of the UK Intensive Care Society. All responses were anonymous in terms of the individual and their place of work. Both quantitative and qualitative data were collected for analysis. Reminder emails were sent to all consultant members 2 and 10 weeks after the initial invitation to encourage participation.

The survey questions are summarised in the online supplementary section.

Descriptive statistical data are presented as mean $(\mathrm{SD})$, median (IQR) and percentages. Correlations were tested using Spearman's rank correlation coefficient.

\section{RESULTS}

\section{Demographic data}

Responses were received from 339 of approximately 1500 consultants surveyed (23\%). Only 266 respondents completed the survey in full $(266 / 339=78.4 \%)$. Consultant experience in intensive care medicine varied with a median number of years practising of 14 (range 1-35). Respondents reported a median number of staffed level 3 beds (beds where patients may receive advanced respiratory support) per unit of 8 (range 2-40, IQR 6-12), with an average of $69.5 \%(\mathrm{SD} \pm 17)$ of beds estimated to be occupied by intubated, mechanically ventilated patients at any one time. There was a wide case mix reported within the units. Mean case load is illustrated in figure 1 . Responses were received from 28 consultants (8.3\%) working in specialist units (21 specialist cardiothoracic and 7 specialist neurology/neurosurgery) where $100 \%$ of patients were from the relevant specialty.

\section{Diagnosis}

\section{Clinical criteria}

Respondents were asked to list criteria they considered to be mandatory for a diagnosis of VAP. A wide variety of responses were received. When respondents' answers were compared with the criteria set out in published guidelines for the diagnosis of VAP 60.6\% (163/269) of respondents matched the Canadian Thoracic Society guidelines, 55.3\% (149/269) the American Thoracic Society guidelines, 49.1\% (132/269) the HELICS (Hospitals in Europe for Infection Control through Surveillance) criteria and 28.3\% (76/269) the Guidelines from the British Society of Antimicrobial Therapy (figure 2). In total 33.1\% (89/269) of respondents did not include CXR appearances within the list of criteria they considered mandatory for a diagnosis of VAP.

\section{Microbiological sampling and bronchoscopic technique}

Respondents were asked to choose one option (from those shown in figure 3) which best reflected their current practice when suspecting a diagnosis of VAP. All respondents indicated that some form of microbiological confirmation should be sought with the majority of consultants, 58\% (156/269) indicating that they would take an endotracheal aspirate (ETA) prior to starting empirical antibiotics.

In terms of experience in bronchoscopy $74.1 \%$ (200/270) of respondents reported that they personally
Figure 1 Mean case load within respondent's intensive care unit.

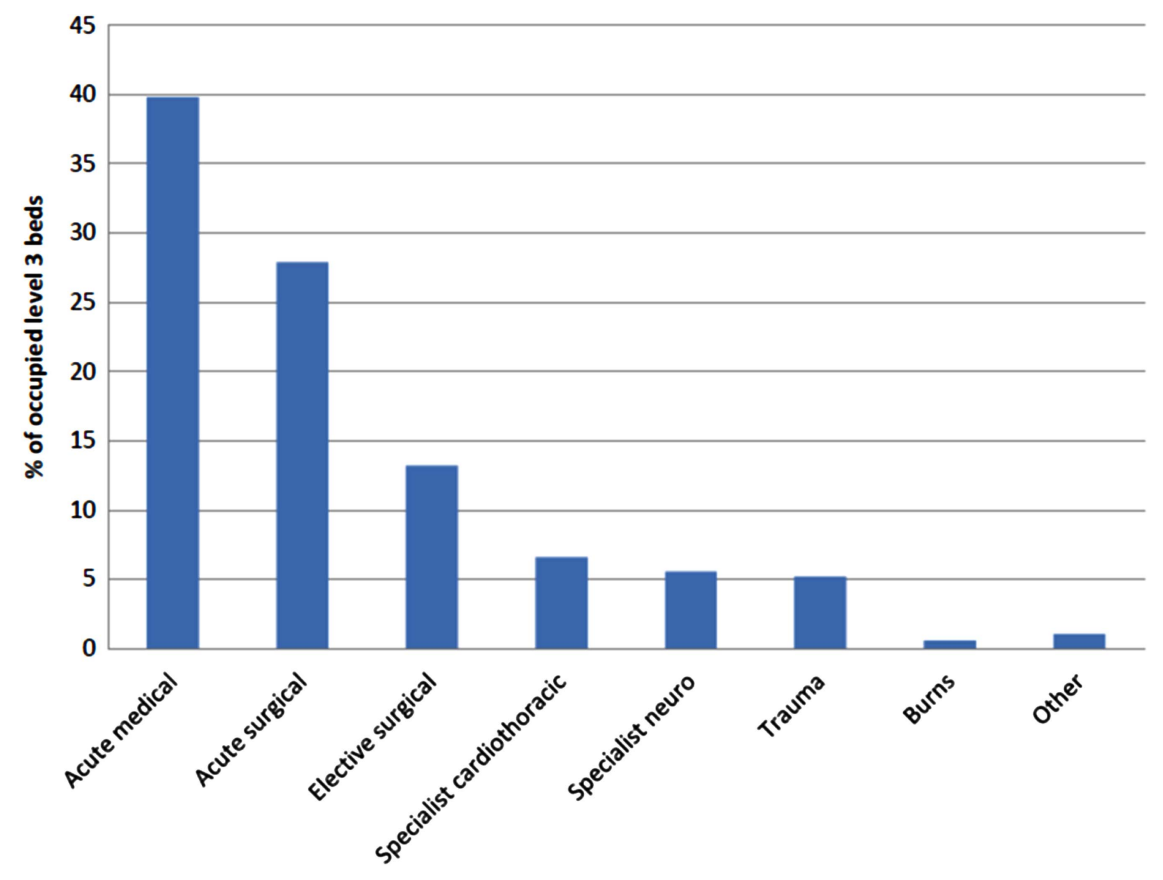




\begin{tabular}{|c|c|c|c|}
\hline Guideline & Radiological Criteria & Clinical Criteria & Clinical Criteria \\
\hline $\begin{array}{l}\text { American Thoracic } \\
\text { Society and Infectious } \\
\text { Diseases Society of } \\
\text { America }\end{array}$ & $\begin{array}{l}\text { Presence of new or progressive } \\
\text { radiographic infiltrates }\end{array}$ & $\begin{array}{l}\text { AND at least } 2 \text { of } \\
\text { 1. Fever }>38^{\circ} \mathrm{C} \\
\text { 2. White cell count }>12,000 / \mathrm{mm}^{3} \text { or } \\
<4000 / \mathrm{mm}^{3} \\
\text { 3. Purulent secretions }\end{array}$ & \\
\hline $\begin{array}{l}\text { British Society of } \\
\text { Antimicrobial } \\
\text { Chemotherapy }\end{array}$ & New or persistent infiltrate on CXR & $\begin{array}{l}\text { AND/OR } \\
\text { Purulent tracheal secretions }\end{array}$ & $\begin{array}{l}\text { AND } \\
\text { Increased } \mathrm{O}_{2} \text { requirement AND } \\
\text { Core temperature }>38.3^{\circ} \mathrm{C} \text { AND } \\
\text { Blood leucocytosis }\left(>10,000 / \mathrm{mm}^{3}\right) \text { or leucopaenia } \\
\left(<4,000 / \mathrm{mm}^{3}\right)\end{array}$ \\
\hline $\begin{array}{l}\text { Association of Medical } \\
\text { Microbiology and } \\
\text { Infectious Disease } \\
\text { Canada and Canadian } \\
\text { Thoracic Society }\end{array}$ & $\begin{array}{l}\text { One of the following abnormalities } \\
\text { on CXR } \\
\text { 1. Evidence of alveolar infiltrates OR } \\
\text { 2. Evidence of air bronchograms OR } \\
\text { 3. New or worsening infiltrates }\end{array}$ & $\begin{array}{l}\text { AND } 2 \text { or more of } \\
\text { 1. Temperature }>38^{\circ} \mathrm{C} \text { or }<36^{\circ} \mathrm{C} \\
\text { 2. Leukopaenia or leucocytosis } \\
\text { 3. Purulent tracheal secretions } \\
\text { 4. Decreased } \mathrm{PaO}\end{array}$ & \\
\hline $\begin{array}{l}\text { Hospitals in Europe } \\
\text { linked for Infection } \\
\text { Control through } \\
\text { Surveillance project } \\
\text { (HELICS) }\end{array}$ & $\begin{array}{l}\text { Two or more serial chest X-rays or } \\
\text { CT-scans with a suggestive image of } \\
\text { pneumonia for patients with } \\
\text { underlying cardiac or pulmonary } \\
\text { disease. } \\
\text { In patients without underlying } \\
\text { cardiac of pulmonary disease one } \\
\text { CXR or CT scan is sufficient }\end{array}$ & $\begin{array}{l}\text { AND at least one of the following } \\
\text { 1. Fever }>38{ }^{\circ} \mathrm{C} \text { with no other cause } \\
\text { 2. Leucopaenia }(<4,000 \mathrm{WCC} / \mathrm{mm} 3) \text { or } \\
\text { leucocytosis ( }>12,000 \mathrm{WCC} / \mathrm{mm} 3)\end{array}$ & $\begin{array}{l}\text { AND at least one of the following } \\
\text { 1. New onset of purulent sputum, or change in character of } \\
\text { sputum (colour, odour, quantity, consistency) } \\
\text { 2. Cough or dyspnoea or tachypnoea } \\
\text { 3. Suggestive auscultation (rales or bronchial breath sounds), } \\
\text { monchi, wheezing } \\
\text { 4. Worsening gas exchange (eg } 02 \text { desaturation or increased } \\
\text { oxygen requirements or increased ventilation demand) }\end{array}$ \\
\hline
\end{tabular}

Figure 2 Recognised criteria for diagnosis of ventilator-associated pneumonia (CXR, chest X-ray).

undertook bronchoscopy within the ICU. Only $27.1 \%$ (73/269) performed bronchoscopic sampling in cases of suspected VAP. The estimated number of bronchoscopies performed per month per unit varied widely with a rate per level 3 bed of $0-5.8$ (mean $0.89, \mathrm{SD} \pm 0.82$ ). There was little consensus in the reported technique for bronchoscopic sampling. The reported volume of saline used to perform a BAL ranged from 5 to $500 \mathrm{~mL}$ (median $20 \mathrm{~mL}$, IQR 20-40) with only 9.6\% (20/208) of respondents instilling $>100 \mathrm{~mL}$. In terms of the sampling site respondents were asked to identify which lobe/ segment they would lavage in a patient with diffuse bilateral shadowing on CXR. The most frequently cited locations were both lower lobes $(27.3 \%, 57 / 209)$, right lower lobe $(16.3 \%, 34 / 209)$, or the right middle lobe $(13.4 \%$, $28 / 209)$, while 22 respondents $(10.9 \%)$ stated that they would lavage all lobes. 24.5\% (49/200) of respondents who perform diagnostic bronchoscopy felt that they were not adequately trained in the procedure with $9.5 \%$ $(19 / 200)$ stating they had received no training at all. The level of confidence in performing BAL was reported to be high, however, with a mean score of 8.3/ $10 \quad \mathrm{SD} \pm 1.7$ on a linear scale of $0-10$ where 0 represented no confidence and 10 represented $100 \%$ confidence). This compared to confidence levels of 4.7/10 $(\mathrm{SD} \pm 2.6)$ for recognition of a tumour, $1.8 / 10(\mathrm{SD} \pm 3.0)$ for endobronchial biopsy and 8.4/10 $(\mathrm{SD} \pm 1.5)$ for clearance of impacted mucus. There was no significant correlation between years of experience in intensive care medicine and confidence in performing BAL $\left(r_{s}=0.013\right.$, $\mathrm{p}=0.85$ ).

Data were collected about the availability of qualitative and quantitative microbiology services within respondents' hospitals (figure 4). Microbiology departments were said to issue qualitative reports only by $29.7 \%$ (80/269) of respondents, as compared with semiquantitative reporting $(37.9 \%, 102 / 269)$ and quantitative reporting $(18.6 \%$, $50 / 269) .13 .8 \%(37 / 269)$ of respondents were unsure of the nature of microbiology services available within their hospital.

\section{Chest X-ray}

Data were gathered in relation to the frequency of, and indications for, CXR in ventilated patients on ICU. In total, $76.7 \%$ (204/266) stated they only perform CXRs on ventilated patients when considered clinically indicated, $13.5 \%$ (36/266) reported requesting a CXR on patients routinely every $3-4$ days, $5.3 \%$ (14/266) every other day, $2.6 \%(7 / 266)$ once a week and $1.9 \%(5 / 266)$ on a daily basis. The features reported as most likely to be considered an indication for a CXR in a ventilated patient were new signs on auscultation and a rise in required inspired oxygen concentration. These were followed in order of likelihood by; the presence of new purulent secretions, a new temperature, a new or increasing inotrope requirement, and a new rise in white cell count (WCC).

Data were collected regarding the level of reporting of CXRs on the ICU (figure 5). A total of $46.2 \%(123 / 266)$ stated that on their unit CXRs are reported by ICU staff, with interesting CXRs discussed with a radiologist in person or at an X-ray meeting (selected reporting). $18.8 \%(50 / 266)$ reported that CXR interpretation was done entirely by ICU staff (no reporting), 18.1\% (48/ 266) by a radiologist when specifically requested to do so (reporting by request) and $16.9 \%(45 / 266)$ stated all 


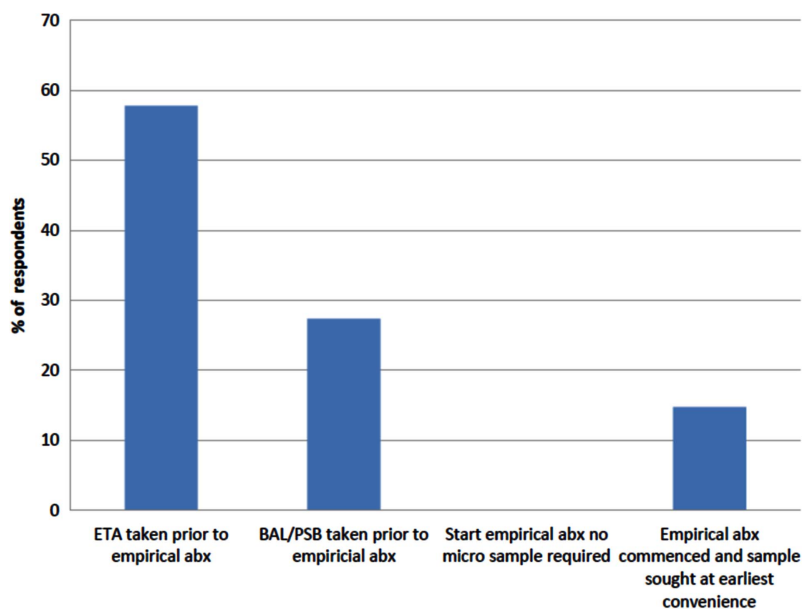

Figure 3 Current practice when suspecting a diagnosis of ventilator-associated pneumonia (abx, antibiotics; ETA, endotracheal aspirate; BAL, bronchoalveolar lavage; PSB, protected specimen brush).

CXRs on their unit were reported by a radiologist (full reporting).

Respondents were asked to indicate their level of confidence in interpreting CXRs performed on intubated, mechanically ventilated patients. The mean score was $8.4 / 10(\mathrm{SD} \pm 1.1)$ on a linear scale of $0-10$ where 0 represented no confidence and 10 represented $100 \%$ confidence. There was no significant correlation between confidence in interpreting CXRs and years of experience in ICU $\left(r_{s}=0.079, p=0.199\right)$.

\section{Treatment}

\section{Pathogens}

Respondents were asked to list what they considered to be the commonest organism causing VAP within their unit. The organism most frequently cited was Pseudomonas aeruginosa $(30.1 \%, 81 / 269)$, followed by Enterobacteriaceae (35.7\%, 96/269; including 'coliforms' (20.8\%, 56/269),

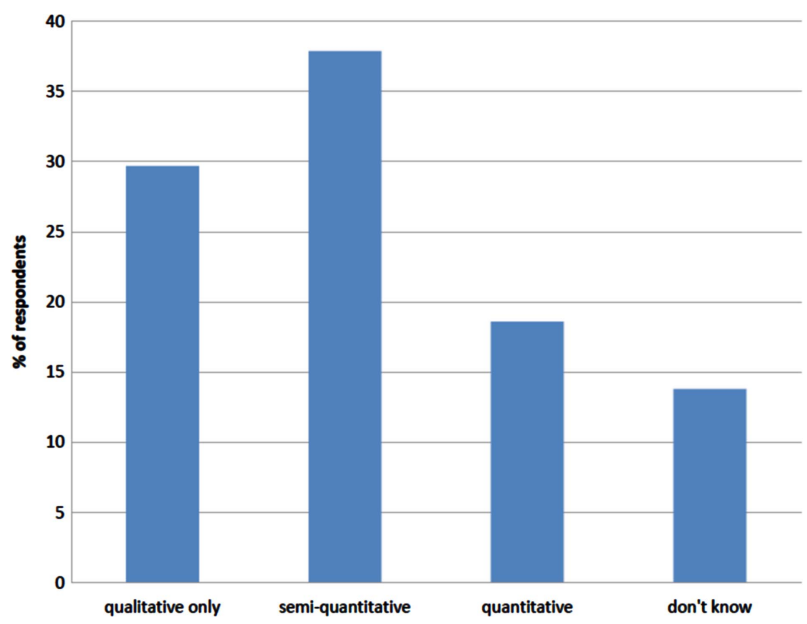

Figure 4 Availability of microbiology services within respondents' hospitals.

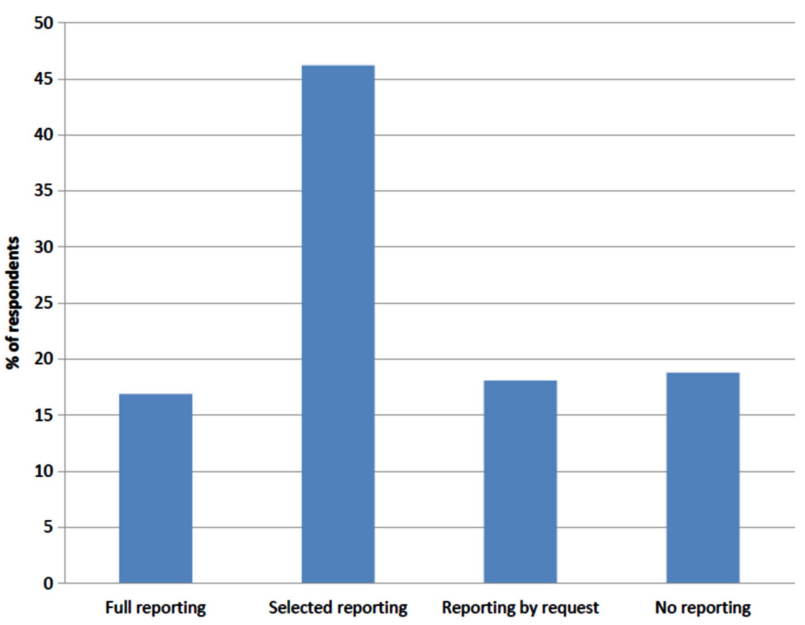

Figure 5 Level of reporting of chest X-rays on the intensive care unit.

Escherichia coli (10.8\%, 29/269), Klebsiella spp (3.3\%, 9/269) and Enterobacter cloacae $(0.7 \%, 2 / 269))$ and methicillinsensitive Staphylococcus aureus (10.8\%, 29/269). Fungal and viral infections were mentioned infrequently $(<1 \%)$.

\section{Antibiotic therapy}

A single agent antibiotic regimen was identified in the majority of cases as being the usual empirical antibiotic therapy $(78.8 \%, 212 / 269)$. Piperacillin-tazobactam was the most frequently reported antibiotic, $(69.9 \%$ (188/ $269)$ of respondents) followed by meropenem (24.2\%, $65 / 269)$. Forty-three different single or double agent antibiotic regimens were listed as being usually prescribed empirical antibiotic therapy in cases of suspected VAP. The 15 most frequently cited antibiotic regimens are illustrated in figure 6. Median reported duration of antibiotic therapy for the treatment of VAP was 6 days (IQR 5-7). Prescribed courses ranged from 3 to 14 days in duration.

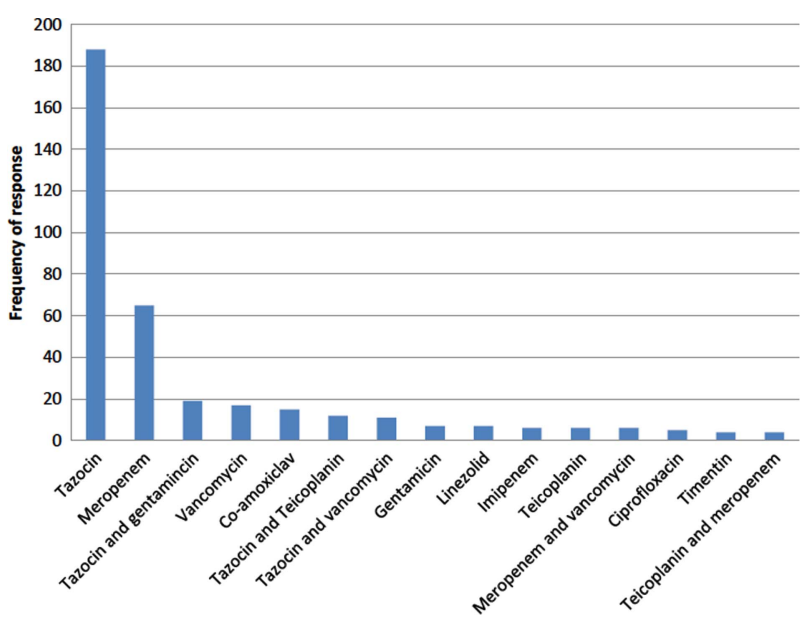

Figure 6 Reported empirical antibiotic selection in cases of suspected ventilator-associated pneumonia. 


\section{DISCUSSION}

The results of this study show that there continues to be wide variation in practice in relation to the investigation, diagnosis and treatment of VAP in the UK. Although the overall response rate was low, comparison with a PubMed search of surveys of ICU consultants over the past 10 years showed that responses were received from a broadly representative spectrum of consultants in terms of clinical experience and case load. This suggests that the data gathered are generally reflective of current UK consultant practice. ${ }^{13-16}$

It is well recognised that diagnosis of VAP is extremely difficult on clinical grounds alone. ${ }^{317}$ There is significant overlap in the signs and symptoms associated with VAP and many other conditions affecting patients on ICU. Clinical criteria such as a new or persistent alveolar infiltrates on CXR in association with purulent tracheal secretions, increasing oxygen requirements, temperature $>38^{\circ} \mathrm{C}$ and $\mathrm{WCC}>10000 / \mathrm{mm}^{3}$ or $<4000 / \mathrm{mm}^{3}$ have been incorporated into guidelines and clinical scoring systems to aid in the diagnosis. ${ }^{1012} 17$ Despite such guidance surrounding the use of clinical criteria however, there was little consensus among respondents regarding those criteria considered mandatory for diagnosis, with only $60.6 \%$ of respondents listing criteria fulfilling at least one of the national guideline definitions for VAP based on clinical criteria. A total of $33.1 \%(89 / 269)$ of respondents did not consider a CXR to be required which is contrary to guideline recommendations stating that all patients with suspected VAP should have a CXR performed to look for the presence of new infiltrates. ${ }^{10-12}$

The radiological diagnosis of VAP is also challenging with low diagnostic sensitivity and specificity of CXR signs in ventilated patients leading to difficulties in interpretation. The only sign to correlate well with the presence of pneumonia is the air bronchogram but even the specificity of this is reduced when coexistent acute respiratory distress syndrome is present. ${ }^{18}$ We are unaware of data comparing the diagnostic accuracy of radiologists and intensivists in the setting of suspected VAP, however data from the pneumonia literature generally suggests that interobserver variability in CXRs is high, and that radiologists probably provide greater diagnostic accuracy. ${ }^{19} 20$ Despite this only $16.9 \%$ of respondents had access to routine reporting of CXRs by a radiologist and confidence in interpreting CXRs was reported to be high with a mean score of 8.4/10.

In terms of microbiological sampling, the majority of respondents reported that their usual practice was to take an ETA for culture prior to starting empirical antibiotics. Colonisation of the proximal airways is common in intubated patients. Non-quantitative culture of pathogens from ETAs commonly reflects such colonisation rather than a pneumonic process. Qualitative ETAs are known to have high sensitivity and low specificity for the diagnosis of VAP, so while they may have a role in excluding VAP, their use for diagnostic purposes is associated with a high rate of false positives and excessive use of unnecessary antibiotics. $^{3} 10 \quad 21$ The suggestion that approximately $50 \%$ of respondents do not have access to quantitative or semiquantitative culture in decisionmaking may therefore have important consequences. Although there are few studies directly comparing the use of qualitative versus quantitative ETA, a diagnostic cut-off of $>10^{6}$ colony-forming units (CFU) per millilitre has been shown to significantly increase the specificity of ETA. ${ }^{3} 21$ Increased access to quantitative microbiology reporting may, therefore, reduce inappropriate antibiotic prescribing in this situation, however, an associated decrease in sensitivity, may put some patients at risk.

Similarly, non-quantitative BAL samples are hard to interpret whereas culture of pathogens at $>10^{3} \mathrm{CFU} / \mathrm{mL}$ from protected specimen brush samples or at $>10^{4}$ $\mathrm{CFU} / \mathrm{mL}$ from BAL fluid appear to increase diagnostic accuracy. $^{3}{ }^{22}$ For example, pathogens cultured at $>10^{4}$ $\mathrm{CFU} / \mathrm{mL}$ from BAL fluid had sensitivity of $91 \%$ and specificity of $78 \%$ for the microbiological confirmation of infection in lung tissue, which in turn correlated with histological evidence of VAP. ${ }^{23}$

Considerable debate continues as to whether bronchoscopic sampling is indicated for the diagnosis of VAP. $^{24-27}$ Despite evidence showing that the sensitivity and specificity of bronchoscopic sampling are superior to ETA, benefits in terms of patient outcomes have been inconsistent in randomised trials. A recent meta-analysis has not shown differences in mortality, length of stay or antibiotic changes. ${ }^{28}$ Bronchoscopic sampling is associated with a lower rate of positive culture among patients with suspected VAP compared with ETA. ${ }^{24}$ Discontinuation of antibiotics in the face of negative BAL culture has been shown to be safe and result in lower antibiotic use and potentially fewer antibiotic-resistant pathogens. ${ }^{29}$ This important potential benefit has not been adequately evaluated in the meta-analysis and reductions in antibiotic use, measured by an increase in antibioticfree days, is probably a more valid outcome measure than mortality for future VAP trials.

Relatively little is known about the general quality of alveolar sampling in suspected VAP. Our survey suggested huge variation in sampling techniques among the respondents who perform BAL. Guidelines for BAL generally recommend instillation of $100-240 \mathrm{~mL}$ of sterile saline to ensure sampling of the alveolar space. ${ }^{30-32}$ The median instillate described in this survey was $20 \mathrm{~mL}$, with only $9.6 \%(20 / 208)$ of respondents using $\geq 100 \mathrm{~mL}$. This suggests that many BALs may not adequately sample alveolar tissue and may therefore be inappropriate for diagnosing pneumonia. The posterior segment of the right lower lobe is considered the most commonly involved segment in VAP. $^{33}$ Only $43.3 \%$ of respondents who perform BAL reported sampling the right lower lobe when CXR gives no indication of the most involved region of the lung. Finally, respondents' confidence in the ability to perform BAL seemed at variance with the fact that $24.5 \%$ described inadequate training in 
bronchoscopy and $9.5 \%$ no training at all. The overall implication is that in a significant number of cases BAL is unlikely to provide optimal alveolar sampling.

Together, the data pertaining to CXRs, microbiological analysis and BAL suggest that an agreed optimal approach to the diagnosis of VAP is lacking in the UK. Few data are available to determine whether this situation is prevalent in other healthcare systems, but it seems likely that similar circumstances will be duplicated in at least some other countries. The clinical implications may be far-reaching. Several studies have shown that objective evidence for VAP is only obtained between $20 \%$ and $42 \%$ of patients in whom the condition was suspected on clinical grounds. ${ }^{34-36}$ The overall trend for decision-making based on non-quantitative microbiology from ETA (or from small volume 'BAL' which has sampled the proximal airways) would tend to favour false-positive diagnoses and the use of unnecessary empirical antibiotics. Another important implication is that the heterogeneity of diagnostic approaches will impact on the reported incidence of VAP, significantly undermining the value of this index as a meaningful performance indicator in healthcare.

While our results suggest shortcomings in the diagnosis of VAP in current practice, several limitations must be considered in their interpretation. In particular we received a $23 \%$ response rate which is clearly too low to be entirely confident that our findings are representative. The low response rate in itself may potentially reflect a general apathy towards the subject of VAP generated by a lack of agreement with respect to the diagnostic and management approach.

Furthermore, in order to maintain anonymity and survey individual consultant practice we did not request the identity of individuals' place of work so we are unable to comment about differences in practice between units. Finally, the data collected are estimates and opinion and may not reflect an individual's actual practice.

\section{CONCLUSION}

There is wide variation in the diagnosis and management of VAP among UK ICU consultants. The data presented suggest that developing a standardised approach, incorporating increased radiological and microbiological support and delivery of standardised BAL protocols, might improve this situation. Until such time the use of reported VAP rates as a performance indicator within the UK healthcare system may be misleading.
Acknowledgements The authors are grateful to the following people for their help in the completion of this survey: The Critical Care Department, Queen Elizabeth Hospital Gateshead (for help with the pilot survey) and the UK Intensive Care Foundation (for distribution of the survey via their mailing list).

Contributors EB contributed to the study design, survey creation, acquisition of data, data analysis and interpretation, drafting and revising of the manuscript. SVB, ACM, VL, DFM and GDP contributed to the design of the study, survey creation, data analysis and interpretation, drafting and revising of the document. TPH contributed to drafting and revising of the manuscript. AJS contributed to conceiving the idea for the study, the study design, survey creation, data analysis and interpretation, drafting and revising of the manuscript

Competing interests DFM reports personal fees from Consultancy for GlaxoSmithKline, personal fees from Board membership for Orion, grants from the UK NIHR and from the Technology Strategy Board,

Provenance and peer review Not commissioned; externally peer reviewed.

Data sharing statement No additional data are available.

Open Access This is an Open Access article distributed in accordance with the Creative Commons Attribution Non Commercial (CC BY-NC 4.0) license, which permits others to distribute, remix, adapt, build upon this work noncommercially, and license their derivative works on different terms, provided the original work is properly cited and the use is non-commercial. See: http:// creativecommons.org/licenses/by-nc/4.0/

\section{REFERENCES}

1. Rello J, Ollendorf DA, Oster G, et al. Epidemiology and outcomes of ventilator-associated pneumonia in a large US database. Chest 2002:122:2115-21.

2. Kollef M. Ventilator-associated pneumonia: a multivariate analysis. JAMA 1993;270:1965-70.

3. Chastre J, Fagon JY. State of the Art: ventilator-associated pneumonia. Am J Respir Crit Care Med 2002;165:867-903.

4. Klein Klouwenberg PMC, van Mourik MSM, Ong DSY, et al. Electronic implementation of a novel surveillance paradigm for ventilator-associated events: feasibility and validation. Am J Respir Crit Care Med 2014:189:947-55.

5. Safdar N, Dezfulian C, Collard HR, et al. Clinical and economic consequences of ventilator-associated pneumonia-a systematic review. Crit Care Med 2005;33:2184-93.

6. Fagon J-Y, Chastre J, Hance AJ, et al. Nosocomial pneumonia in ventilated patients: a cohort study evaluating attributable mortality and hospital stay. Am J Med 1993;94:281-8.

7. Melsen WG, Rovers MM, Groenwold RHH, et al. Attributable mortality of ventilator-associated pneumonia: a meta-analysis of individual patient data from randomised prevention studies. Lancet Infect Dis 2013;13:665-71.

8. Bekaert M, Timsit JF, Vansteelandt S, et al; Outcomerea Study Group. Attributable mortality of ventilator-associated pneumonia: a reappraisal using causal analysis. Am J Respir Crit Care Med 2011;184:1133-9.

9. Klompas M. Interobserver variability in ventilator-associated pneumonia surveillance. Am J Infect Control 2010;38:237-9.

10. Masterton R, Galloway A, French G, et al. Guidelines for the management of hospital-acquired pneumonia in the UK: report of the working party on hospital-acquired pneumonia of the British Society for Antimicrobial Chemotherapy. J Antimicrob Chemother 2008:62:5-34.

11. American Thoracic Society, Infectious Disease Society of America Guidelines for the management of adults with hospital-acquired, ventilator-associated, and healthcare-associated pneumonia. Am J Respir Crit Care Med 2005;171:388-416.

12. Rostein C, Evans G, Born A, et al; AMMI Canada Guidelines. Clinical practice guidelines for hospital-acquired pneumonia and ventilator-associated pneumonia in adults. Can J Infect Dis Med Microbiol 2008;19:19-53.

13. Macsweeney R, Barber V, Page V, et al. A national survey of the management of delirium in UK intensive care units. QJM 2010;103:243-51.

14. Dushianthan A, Cusack R, Chee N, et al. Perceptions of diagnosis and management of patients with acute respiratory distress syndrome: a survey of United Kingdom intensive care physicians. BMC Anesthesiol 2014;14:87. 
15. Reschreiter $\mathrm{H}$, Maiden $\mathrm{M}$, Kapila A. Sedation practice in the intensive care unit: a UK national survey. Crit Care 2008;12:R152.

16. Thomas E. A national survey of ICU consultant working practices at weekends. Anaesthesia 2004;59:960-66.

17. Tejerina E, Esteban A, Fernandez-Segoviano P, et al. Accuracy of clinical definitions of ventilator-associated pneumonia: comparison with autopsy findings. J Crit Care 2010;25:62-8.

18. Wunderink $\mathrm{R}$, Woldenberg $\mathrm{L}$, Zeiss $\mathrm{J}$, et al. The radiologic diagnosis of autopsy-proven ventilator-associated pneumonia. Chest 1992;101:458-63.

19. Young M, Marrie TJ. Interobserver variability in the interpretation of chest roentenograms of patients with possible pneumonia. Arch Intern Med 1994;154:2729-32.

20. Albaum MN, Hill LC, Murphy M, et al. Inter-observer reliability of the chest radiograph in community-acquired pneumonia. Chest 1996;110:343-50.

21. Conway Morris A, Kefala K, Simpson AJ, et al. Evaluation of the effect of diagnostic methodology on the reported incidence of ventilator-associated pneumonia. Thorax 2009;64:516-22.

22. Torres A, El Ebiary M. Bronchoscopic BAL in the diagnosis of ventilatorassociated pneumonia. Chest 2000;117(Suppl 2):198S-202S.

23. Chastre J, Fagon J-Y, Bornet-Lesco M, et al. Evaluation of bronchoscopic techniques for the diagnosis of ventilator-associated pneumonia. Am J Respir Crit Care Med 1995;152:231-40.

24. Fagon JY, Chastre J, Wolff M, et al. Invasive and noninvasive strategies for the management of suspected ventilator-associated pneumonia. Ann Intern Med 2000;132:621-30.

25. Campbell GD. Blinded invasive diagnostic procedures in ventilatorassociated pneumonia. Chest 2000;117(Suppl 2):207S-11S

26. Wood A, Davit AJ, Ciraulo DL, et al. A prospective assessment of the diagnostic efficacy of blind protective bronchial brushings compared to bronchoscope-directed brushings and blind endotracheal aspirates in ventilator-associated pneumonia. J Trauma 2003;55:825-34.
27. Heyland D, Cook D, Dodek $P$, et al. A randomized trial of diagnostic techniques for ventilator-associated pneumonia. The Canadian Critical Care Trials Group. N Engl J Med 2006;355:619-30.

28. Berton DC, Kalil AC, Teixeira PJZ. Quantitative versus qualitative cultures of respiratory secretions for clinical outcomes in patients with ventilator-associated pneumonia. Cochrane Database Syst Rev 2012;1:CD006482.

29. Raman K, Nailor MD, Nicolau DP, et al. Early antibiotic discontinuation in patients with clinically suspected ventilator-associated pneumonia and negative quantitative bronchoscopy cultures. Crit Care Med 2013;41:1656-63.

30. Haslam P, Baughman R. Report of the European Respiratory Society Task Force: guidelines for measurement of acellular components and standardisation of bronchoalveolar lavage. Eur Respir J 1999;114:245-8.

31. Baselski V, Wunderink R. Bronchoscopic diagnosis of pneumonia. Clin Microbiol Rev 1994;7:533-58.

32. Meduri G, Chastre J. The standardization of bronchoscopic techniques for ventilator-associated pneumonia. Chest 1992;102 (Suppl):557S-64S.

33. Rouby J, Martin De Lassale E, Poete P, et al. Nosocomial bronchopneumonia in the critically ill. Histologic and bacteriologic aspects. Am Rev Respir Dis 1992;146:1059-66.

34. Conway Morris A, Kefala K, Wilkinson TS, et al. Diagnostic importance of pulmonary interleukin-1 $\beta$ and interleukin- 8 in ventilator-associated pneumonia. Thorax 2010;65:201-7.

35. Fagon J, Chastre J, Hance AJ, et al. Detection of nosocomial lung infection in ventilated patients: use of a protected specimen brush and quantitative culture techniques in 147 patients. Am J Respir Crit Care Med 1988;138:110-16.

36. Meduri G, Mauldin GL, Wunderink RG, et al. Causes of fever and pulmonary densities in patients with clinical manifestations of ventilator-associated pneumonia. Chest 1994;106:21-35. 